\title{
Condições de armazenamento e tempo de embebição na germinação de sementes de erva-doce (Pimpinella anisum L.)
}

TAKAHASHI, L.S.A.T.; SOUZA, J.R.P.*; YOSHIDA, A.E.; ROCHA, J.N.

Universidade Estadual de Londrina, Depto. de Agronomia, Centro de Ciências Agrárias. C.P. 6001, 6051-990Londrina,PR.*jose@uel.br

\begin{abstract}
RESUMO: O trabalho teve o objetivo de avaliar o efeito de diferentes condições e períodos de armazenamento e diferentes períodos de embebição na germinação de sementes de erva-doce. As sementes foram armazenadas por $1,3,5,7$ e 9 meses em temperatura ambiente $\left(22 \pm 2^{\circ} \mathrm{C}\right)$ e controlada $\left(10^{\circ} \mathrm{C}\right)$ e em seguida foram submetidas a cinco períodos de embebição $(0,12,24 \mathrm{e}$ 36 horas). Os testes de germinação foram conduzidos em câmara de germinação à temperatura de $25^{\circ} \mathrm{C}$ com fotoperíodo de 8 horas de luz e 16 horas de escuro. $O$ delineamento experimental foi o inteiramente ao acaso com parcelas subdivididas com 4 repetições de 100 sementes. A porcentagem de germinação das sementes armazenadas em temperatura controlada foi maior que aquelas armazenadas em temperatura ambiente. As sementes armazenadas à $10^{\circ} \mathrm{C}$ mantiveram uma porcentagem de germinação de $57,8 \%$ por até cinco meses, e não controlada, $67,0 \%$ por um mês. Períodos crescentes de embebição afetaram negativamente a porcentagem de germinação das sementes de erva-doce.
\end{abstract}

Palav ras-chave: conservação, deterioração, qualidade de sementes

\begin{abstract}
Storage conditions and periods and imbibition times in anise (Pimpinella anisum L.) seed germination. This study aimed to evaluate the effect of different storage conditions and periods and different imbibition times in anise seed germination. Seeds were stored for $1,3,5,7$, and 9 months at room $\left(22 \pm 2^{\circ} \mathrm{C}\right)$ and controlled $\left(10^{\circ} \mathrm{C}\right)$ temperatures and then subjected to five imbibition times $(0,12,24$, and $36 \mathrm{~h})$. Germination tests were carried out in a germination chamber at $25^{\circ} \mathrm{C}$ with photoperiod of $8 \mathrm{~h}$ light: $16 \mathrm{~h}$ dark. The experimental design was completely randomized using split plot with 4 replicates of 100 seeds. Germination percentage was higher in seeds stored at controlled temperature than in those stored at room temperature. Seeds stored at $10^{\circ} \mathrm{C}$ kept a germination percentage of $57.8 \%$ for up to five months, whereas those at uncontrolled temperature kept $67.0 \%$ for one month. Increasing imbibition periods negatively affected anise seed germination percentage.
\end{abstract}

Key words: Conservation, deterioration, seed quality

\section{INTRODUÇÃO}

A erva-doce, Pimpinella anisum L., (Umbelliferae), também conhecida como anis é originária de países da Ásia, Egito e Grécia, e cultivada na Turquia, Rússia, América Latina e Brasil. É uma planta anual, herbácea, ereta (0,30-0,70 m), aromática, apresentando flores brancas e dispostas em umbelas. É utilizada tanto na fitoterapia, como na alimentação, na forma de condimento (Torres, 2004). Para fins medicinais, são usados principalmente frutos, raízes e, algumas vezes, folhas frescas. Seu óleo essencial é extraído de seus frutos (Von Hertwig,
1991; Rodrigues et. al, 2003). Os componentes dessa planta atuamno aparelho digestivo e respiratório, além de estimular as funções biológicas, favorecer a secreção láctea. Também possui efeito dilatador, aumentando a circulação cutânea (Teske \& Trentini, 1995; Lorenzi \& Matos, 2002).

A erva-doce é propagada por sementes, e sua germinação ocorre de duas a cinco semanas após a semeadura. Um processo utilizado para acelerar a sua germinação é a pré-embebição das sementes (Von Hertwig, 1991).

Recebido para publicação em 15/12/2005

Aceito para publicação em 11/11/2008

Rev. Bras. PI. Med., Botucatu, v.11, n.1, p.1-6, 2009. 
A fase de germinação de qualquer semente tem início com a embebição de água que reidrata as sementes e ativa o metabolismo do tecido embrionário (Melo et al., 1979; Mayer \& Poljakoff-Mayber, 1982; Popinigis, 1985; Larcher, 2000). A água penetra através do tegumento da semente, provocando a turgescência das células, o que favorece as trocas gasosas, aumentando a atividade respiratória (Ferreira \& Borghetti, 2004). A absorção de água pela semente provoca, ainda, aumento de seu volume, forçando o rompimento do tegumento e facilitando a emergência das estruturas internas da semente, as quais não teriam força suficiente para rompê-lo (Carvalho \& Nakagawa, 2000).

Estudos sobre a influência da temperatura na germinação das sementes são essenciais para entender os aspectos ecofisiológicos e bioquímicos desse processo (Labouriau, 1983; Bewley \& Black, 1994). Seus efeitos podem ser avaliados a partir de mudanças ocasionadas na porcentagem, velocidade e freqüência relativa de germinação ao longo do tempo de incubação (Labouriau \& Pacheco, 1978). A faixa de temperatura ótima é aquela onde acontece a germinação máxima no menor tempo médio (Labouriau, 1983).

De maneira geral, as condições de cultivo, de colheita, de secagem e de armazenamento definem a qualidade das sementes, assim como o armazenamento. Toda e qualquer semente armazenada sofre deterioração que pode ser mais rápida ou mais lenta, dependendo das características ambientais e das características das próprias sementes. Geralmente a redução da luminosidade, da temperatura e da umidade de ambos, sementes e ambiente, faz com que seu metabolismo seja reduzido e que os microorganismos que as deterioram fiquem fora de ação, aumentando sua longevidade. (Vieira et al., 2001). Assim, O armazenamento tem por objetivo conservar as sementes, preservando suas qualidades físicas, fisiológicas e sanitárias, para posterior semeadura e obtenção de plantas sadias após a germinação (UFSM, 2004).

As sementes de várias espécies podem ser armazenadas por longos períodos sem tratamento, como muitas leguminosas pioneiras, mas outras necessitam preparação para o armazenamento e condições ambientais especiais. Assim, além do tratamento da própria semente, são necessários embalagem e ambiente apropriados. Os principais meios utilizados para o armazenamento de sementes são a câmara fria, a câmara seca e a câmara fria seca, que se adaptam à maioria das situações (Vieira et al., 2001).

A capacidade de armazenamento das sementes varia entre as espécies, entre e dentro de lotes (Groot et al., 2003). Essa tolerância está relacionada à capacidade do organismo em enfrentar o estresse da quase completa perda de água e da reidratação, pelo acúmulo de altos níveis de açúcares (Hoekstra et al., 2003). Acredita-se que estes açúcares são capazes de prevenir mudanças nas fases das membranas e mudanças estruturais das proteínas (Crowe et al., 1998). Assim, as membranas não se rompeme a atividade enzimática é preservada.

Mesmo apresentando alto valor comercial, verifica-se uma carência empesquisas direcionadas ao desenvolvimento de métodos para avaliação do vigor e qualidade fisiológica de sementes de erva-doce (Von Hertwig, 1991). Essas informações são fundamentais para subsidiar os produtores rurais no controle da qualidade fisiológica das sementes, principalmente no que se refere ao planejamento e definição da época ideal de colheita, visando também à produtividade (Dias, 2001). Essas informações poderiam impulsionar o cultivo dessa umbelífera no Estado do Paraná, onde não está totalmente difundida. O trabalho teve o objetivo de avaliar o efeito de diferentes condições e períodos de armazenamento e o tempo de embebição no processo de germinação de sementes de erva-doce.

\section{MATERIAL E MÉTODO}

O experimento foi realizado na Universidade Estadual de Londrina, Paraná, onde sementes comerciais de erva-doce foram submetidas à determinação do grau de umidade do lote, para uma pré-seleção, através do método proposto pela Regra de Análise de Sementes (RAS) (Brasil, 1992). Padronizou-se o tamanho das amostras como sendo $1,0 \mathrm{~g}$ de sementes por recipiente. Os recipientes com as sementes foram colocados em estufa com circulação de ar forçado, à temperatura de $55^{\circ} \mathrm{C}$ por trinta minutos até atingir peso seco constante. Transcorridos os trinta minutos de cada secagem, as três amostras eram retiradas da estufa, colocadas num dessecador por 10 minutos para o resfriamento dos recipientes e, a seguir, pesados em balança analítica com precisão de quatro casas. A determinação do teor de água foi obtida através da fórmula (Brasil, 1992):

$$
\% U=\frac{100(P-p)}{P-t}
$$

$$
\text { onde } \begin{aligned}
\mathrm{P} & =\text { Recipiente }+ \text { tampa }+ \text { semente úmida }(\mathrm{g}) \\
\mathrm{p} & =\text { Recipiente }+ \text { tampa }+ \text { semente } \\
\mathrm{t} & =\text { tara }(\text { recipiente }+ \text { tampa })(\mathrm{g}) \\
& \mathrm{O} \text { delineamento experimental foi } \mathrm{O}
\end{aligned}
$$
inteiramente ao acaso com parcelas subdivididas. Foram realizados dois experimentos em parcelas subdivididas (split plot designs) comquatro repetições 
de 100 sementes, umcom as sementes armazenadas em temperatura ambiente (média anual de $22 \pm 2^{\circ} \mathrm{C}$ ) e o outro com temperatura controlada (câmara fria a $\left.10^{\circ} \mathrm{C}\right)$. As parcelas foram constituídas por quatro períodos de embebição (0, 12, 24 e 36 horas) e as subparcelas por cinco tempos de armazenamento (1, 3, 5, 7 e 9 meses).

Inicialmente, as sementes foram tratadas com fungicida Captan SC ${ }^{\circledR} 5 \%$ (N-Triclorometiltio-4ciclo-hexeno-1,2-dicarboximida), e armazenada por um período de 1, 3, 5, 7e 9 meses a temperatura ambiente ou a temperatura controlada.

Finalizado os períodos de armazenamento, as sementes foram colocadas em copos plásticos de $200 \mathrm{~mL}$, onde foram adicionados $75 \mathrm{~mL}$ de água deionizada, e mantidas por períodos de 0,12, 24 e 36 horas a temperatura ambiente de $20^{\circ} \mathrm{C}$. Após o período de exposição das sementes, estas foram retiradas dos copos e distribuídas sobre papel filtro, em condições de ambiente sem controle de temperatura e umidade relativa do ar, para retirada do excesso de água.

Em seguida, foram montados os testes de germinação com quatro repetições de 100 sementes por tratamento. As sementes foram colocadas sobre três folhas de papel germitest em caixas plásticas transparentes (gerbox), desinfetadas comsolução de hipoclorito de sódio a $10 \%$. As folhas de papel para teste de germinação foram deixadas em estufa a 105C durante 3 horas, e emseguida elas foram umedecidas comágua destilada na proporção de 2,5 vezes o seu peso (Brasil, 1992). As caixas gerbox foramenvoltas por sacos plásticos transparentes, para contenção da umidade do meio, e acondicionados em câmara de crescimento tipo BOD a $25^{\circ} \mathrm{C}$, com fotoperíodo de 8 horas de luz e 16 horas de escuro (Brasil, 1992).

As avaliações foram realizadas no sétimo e no décimo quarto dia após a semeadura (DAS) segundo os critérios estabelecidos pela RAS (Brasil, 1992). Os resultados foram expressos em porcentagem média de plântulas normais. As sementes foram consideradas germinadas quando apresentavam raiz primária superior a $2 \mathrm{~mm}$ de comprimento.

Os dados experimentais coletados foram submetidos à análise de variância, e as médias comparadas pelo teste de Tukey a 5\% de probabilidade. Avariável porcentagem de germinação foi transformada para arc sen $(x / 100)^{1 / 2}$ (Storck et al., 2000).

\section{RESULTADO E DISCUSSÃO}

Verificou-se interação significativa entre os diferentes períodos de embebição das sementes e os períodos de armazenamento na SC condições de temperatura controlada $\left(10^{\circ} \mathrm{C}\right)$ e temperatura ambiente $\left(22 \pm 2^{\circ} \mathrm{C}\right)$ (Tabelas 1 e 2$)$.

Para as sementes armazenadas à temperatura controlada de $10^{\circ} \mathrm{C}$ a germinação começou a diminuir a partir do sétimo mês, independente do tempo de embebição. Essa porcentagem de germinação se manteve até o quinto mês, mesmo para aquelas sementes que sofreram embebição de até 24 horas; um período maior de embebição acima de 24 horas provocou queda significativa na porcentagem de germinação a partir do quinto mês (Tabela 1).

A hidratação das sementes provoca a retomada do metabolismo, mas as atividades metabólicas no início do processo não atingiram a eficiência esperada, pois há necessidade da atuação de mecanismos de reparo dos componentes celulares, naturalmente danificados com a desidratação durante a maturação, em intensidade proporcional às adversidades do ambiente. À medida que se hidrata, a semente torna-se sensívelàs baixas temperaturas e a embebição rápida. Sementes desidratadas no início da embebição têm maior probabilidade de retomar as atividades metabólicas quando reidratadas (Marcos Filho, 2005).

As porcentagens de germinação observadas neste trabalho apresentaramvalores menores do que o detectado nos experimentos de Stefanello et al.

TABELA 1. Porcentagem de germinação de sementes de erva-doce armazenadas por diferentes períodos a temperatura $\left(10^{\circ} \mathrm{C}\right)$ e submetidas a diferentes períodos de embebição. Londrina. 2007.

\begin{tabular}{|c|c|c|c|c|c|}
\hline \multirow{2}{*}{$\begin{array}{l}\text { Tempo de } \\
\text { em bebição } \\
\text { (horas) }\end{array}$} & \multicolumn{5}{|c|}{ Período de armazenamento (meses) } \\
\hline & 1 & 3 & 5 & 7 & 9 \\
\hline 0 & $63,0 \mathrm{~A}$ a* & $62,5 \mathrm{~A}$ a & $57,8 \mathrm{AB}$ ab & $57,0 \mathrm{~B}$ a & $56,9 \mathrm{~B} \mathrm{a}$ \\
\hline 12 & $59.5 \mathrm{~A} \mathrm{a}$ & $59.3 \mathrm{~A}$ a & $62,3 \mathrm{~A}$ a & $53.9 \mathrm{~B} \mathrm{a}$ & $50.2 \mathrm{~B} \quad \mathrm{~b}$ \\
\hline 24 & $60,3 \mathrm{~A} a$ & $60,7 \mathrm{Aa}$ & $59,7 \mathrm{~A}$ ab & $54,0 \mathrm{~B} \mathrm{a}$ & $50,2 \mathrm{~B} \quad \mathrm{~b}$ \\
\hline 36 & $59,2 \mathrm{~A}$ a & $60,4 \mathrm{~A} a$ & $56,5 \mathrm{~A}$ & $45,5 B \quad b$ & $44,5 \mathrm{~B}$ \\
\hline
\end{tabular}

*Médias seguidas da mesma letra maiúscula na linha, e minúscula na coluna, não diferem entre si pelo teste de Tukey a $5 \%$ de probabilidade. C. V. (\%): 4,00 DMS $=2,66$ 
(2006), que foi de $76 \%$; e maiores que o obtido por Torres (2004), de 50\%, trabalhando com sementes de erva-doce.

As sementes de erva doce armazenadas em condições ambientes apresentaram reduções significativas na porcentagem de germinação a partir do primeiro mês. Nas sementes armazenadas em temperatura ambiente, o maior valor de porcentagem de germinação $(67 \%)$ foi obtido quando as sementes não sofreram embebição e foram armazenadas por apenas um mês (Tabela 2).

Segundo Mayer \& Poljakoff-Mayber (1982), as baixas temperaturas prolongam a viabilidade das sementes como regra geral. Ambientes com temperaturas mais elevadas provocam aumento na taxa respiratória das sementes, e conseqüentemente aumento significativo na umidade relativa do ar no interior da embalagem, com isso há um aceleramento da atividade microbiana e uma deterioração das sementes (Garcia \& Lima, 2000; Popinigis, 1985).

Os períodos de embebição que as sementes de erva doce foram submetidas na condição de armazenamento sem controle de temperatura redużram significativamente a germinação (Tabela 2).

Esses resultados discordam dos obtidos por Coelho \& Azevedo (2000) e Ferronato et al. (1997), que trabalharam, respectivamente, commangava brava (Lafoensia pacari ST. Hill.) e marmelada bola (Alibertia edulis L.C.); as duas espécies responderam muito bemà imersão das sementes emágua por 24 horas.

Reddy \& Singh (1992) verificaram que o aumento do período de embebição diminui a germinação de sementes de picão-preto e cessa aos 28 dias após a semeadura. Todavia, trabalhando com a mesma espécie, Chivinge (1996) constatou que apesar das sementes iniciarem o processo de germinação em menos de 24 horas de embebição, a maior porcentagem de germinação (59\%) ocorreu somente após cinco dias de embebição.

Existe uma diversidade de comportamento das sementes medicinais, em relação à embebição. Bezerra et al. (2006) verificaram que a germinação

TABELA 2. Porcentagem de germinação de sementes de erva-doce armazenadas por diferentes períodos a temperatura ambiente e submetidas a diferentes períodos de embebição. Londrina. 2007.

\begin{tabular}{|c|c|c|c|c|c|}
\hline \multirow{2}{*}{$\begin{array}{l}\text { Tempo de } \\
\text { embebiçáo } \\
\text { (horas) }\end{array}$} & \multicolumn{5}{|c|}{ Período de amazenamento (meses) } \\
\hline & 1 & 3 & 5 & 7 & 9 \\
\hline $\mathbf{0}$ & $67,0 \mathrm{~A} \mathrm{a}^{*}$ & $56.7 \mathrm{Ba}$ & $49,5 \mathrm{Cb}$ & $42,4 \mathrm{D} \mathrm{a}$ & $41,6 \mathrm{Da}$ \\
\hline 12 & $56,8 \mathrm{~A} \mathrm{~b}$ & $50.6 \mathrm{~B} \mathrm{~b}$ & $46,3 \mathrm{~B}$ ab & $45,2 \mathrm{~B} \mathrm{a}$ & $37,9 \mathrm{C}$ ab \\
\hline 24 & $56,7 \mathrm{~A} \quad \mathrm{~b}$ & $56: 1 \mathrm{Aa}$ & $50,4 \mathrm{~B}$ a & $45,1 \mathrm{~B} \mathrm{a}$ & $34,7 \mathrm{C} \quad \mathrm{b}$ \\
\hline 36 & $48,3 \mathrm{~A}$ & $49.7 \mathrm{~A} \mathrm{~b}$ & $45,8 \mathrm{~A} \mathrm{ab}$ & $46,8 \mathrm{~A} \mathrm{a}$ & $35,1 \mathrm{~B} \quad \mathrm{~b}$ \\
\hline
\end{tabular}

*Médias seguidas da mesma letra maiúscula na linha, e minúscula na coluna, não diferem entre si pelo teste de Tukey a $5 \%$ de probabilidade. C.V. (\%): 4,00 $\mathrm{DMS}=2,76$

das sementes de macela aumentou linearmente com o tempo de embebição. Por outro lado, a germinação das sementes de macela (Egletes viscosa) não embebidas foi superior a da erva-formigueiro (Eupatorium laevigatum Lam.), Mikania cordifolia Willd. $(34,6 \%)$ e inferiores à de cravo-de-defunto (Tagetes minuta L.), arnica (Stenachaenium campestre Baker) e agrião do brejo (Eclipta alba Hassk.), observadas por Ferreira et al. (2001), sob temperatura alternada de $30-20^{\circ} \mathrm{C}$ (8h de luza $30^{\circ} \mathrm{C} /$ 16 h de escuro a $\left.20^{\circ} \mathrm{C}\right)$. Resultados semelhantes foram verificados por Davies (1999) emcarqueja (Baccharis trimera Less.) conduzida a temperatura ambiente.

As porcentagens de germinação das sementes armazenadas em temperatura controlada foram maiores que aquelas armazenadas em temperatura ambiente (Tabelas 1 e 2). Resultado semelhante foi obtido por Garcia \& Lima (2000) trabalhando com sementes de copaíba (Copaifera multijuga), e também por Arrigoni-Blank et al. (1997) com sementes de casaqueira (Campomanesia rufa). A longevidade de sementes é bastante influenciada pelas condições de armazenamento, sobretudo pelo teor de água e pela temperatura ambiente (Villela \& Peres, 2004).

Maluf \& Pisciottano-Ereio (2005) também verificaram que 0 armazenamento em condições controladas (temperatura de $8 \pm 2^{\circ} \mathrm{C}$ e em sacos plásticos) quando comparado ao armazenamento em condições não controladas (temperatura ambiente), revelou redução da germinação final das sementes de cambuci (Campomanesia phaea) de 99,3\% para $57,8 \%$.

Almeida (1981), Figueiredo et al. (1982) e Gomes (1992) ressaltaramque a qualidade fisiológica das sementes armazenadas é melhor quando há controle de temperatura e de umidade relativa do ar. Além disso, temperaturas baixas diminuem o metabolismo celular, refletindo no prolongamento da longevidade das sementes (Figliolia et al., 1993; 
Ferreira \& Borghetti, 2004).

Nas condições que os experimentos foram conduzidos pode-se concluir que as sementes de erva-doce armazenadas à temperatura de $10^{\circ} \mathrm{C}$ mantêma porcentagem de germinação durante cinco meses enquanto aquelas armazenadas à temperatura ambiente $\left(22 \pm 2^{\circ} \mathrm{C}\right)$ mantêm o potencial de germinação apenas por um mês. Já o aumento no tempo de embebição das sementes de erva-doce afeta negativamente a porcentagem de germinação.

\section{REFERÊNCIA}

ALMEIDA, F.A.C. Efeitos da temperatura e umidade relativa do ar sobre a germinação, vigor e teor de umidade de sementes armazenadas de algodão. 1981. 65p. Dissertação (Mestrado) - Curso de Pós-graduação em Agronomia, Universidade Federal da Paraíba, Campina Grande.

ARRIGONI-BLANK, M.F. et al. Armazenamento e viabilidade de sementes de Campomanesia rufa. Ciência e Agrotecnologia, v.21, n.1, p.85-90, 1997.

BEZERRA, A.M.E. et al. Efeito da pré-embebição e aplicação de ácido giberélico na germinação de sementes de macela. Revista Brasileira de Sementes, v.28, n.3, p.185-90, 2006

BEWLEY, J.D.; BLACK, M. Seeds: physiology of development and germination. New York: Plenum Press, 1994. 445p.

BRASIL. Ministério da Agricultura e Reforma Agrária. Regras para análise de sementes. Brasília: SNDA/ DNDV/CLAV, 1992. 365p.

CARVALHO, N.M.; NAKAGAWA, J. Sementes: ciência, tecnologia e produção. 4.ed. Jaboticabal: FUNEP, 2000. 502p.

CHIVINGE, O.A. Studies on the germination and seedling emergence of Bidens piloa and its response to fertilizer application. Transactions of the Zimbabwe Scientific Association, v.70, p.1-5, 1996.

COELHO, M.F.B.;AZEVEDO, R.A.B. Efeito de tratamentos pré-germinativos e substratos em Lafoensia pacari Saint. Hil. - Lythraceae. In: SIMPÓSIO DE PLANTAS MEDICINAIS DO BRASIL, 16., 2000, Recife. Anais... Recife: UFPE, 2000. p.73.

CROWE, J.H. et al. Are freezing and dehidratation similar stress vectors? A comparison of modes of interation of stabilizing solutes with biomolecules. Criobiology, v.27, p.219-31, 1998.

DAVIES, P. Experimentation on the propagation of Bacharis trimera (Less.) DC., Compositae (Carqueja). In:WORLD CONGRESS ON MEDICINALAND AROMATIC PLANTS FOR HUMAN WELFARE, 2., 1999, Mendoza. Proceedings... Mendoza:ISHS, 1999. p.117-20.

DIAS, D.C.F. Maturação de sementes. Revista Seed News, v.5, n.6, p.22-4, 2001.

FERREIRA, A.G;BORGHETTI, F. Germinação: do básico ao aplicado. Porto Alegre: Artmed, 2004. 323p.

FERREIRA, G.A. et al. Germinação de sementes de Asteraceae nativas do Rio Grande do Sul, Brasil. Acta
Botânica Brasílica, v.15, n.2, p.231-42, 2001

FERRONATO, A.; COELHO, M.F.B.; DIGNART, S. Germinação e viabilidade de sementes de marmeladabola (Alibertia edulis L. C. Rich - Rubiaceae), espécie de uso medicinal em Mato Grosso. Revista Agricultura Tropical, v.3, n.1, p.38-47. 1997.

FIGLIOLIA, M.B.; OLIVEIRA, E.C.; PIÑA RODRIGUES, F.C.M. Análise de sementes. In: AGUIAR, I.B.; PIÑA RODRIGUES, F.C.M.; FIGLIOLIA, M.B. (Eds.). Sementes florestais tropicais. Brasília: ABRATES, 1993. p.137-74. FIGUEIREDO, F.J.C. et al. Conservação de sementes de caupi. Belém: EMBRAPA-CPATU (Circular Técnica número 31). 1982. 23p.

GARCIA, L.C.; LIMA, D. Comportamento de sementes de Copaifera multijuga durante o armazenamento. Acta Amazônica, v.30, n.3, p.369-75, 2000.

GOMES, J.P. Comportamento da germinação e vigor de sementes de algodão herbáceo em diferentes tipos de embalagens, tratamentos e condições de conservação durante a sua armazenagem.1992. 89p. Dissertação (Mestrado) - Curso de Pós-graduação em Agronomia, Universidade Federal da Paraíba, Campina Grande.

GROOT, S.P.C. et al. Gene expression during loss and regaining of stress tolerance at seed priming and drying. In: NICOLÁS, G. et al. (Eds.). The biology of seeds: recent research advances. Cambridge: CAB International, 2003. p.279-87.

HOEKSTRA, F.A.; GOLOVINA, E.A.; NIJSSE, J. What do we know about desiccation tolerance mechanism? In: NICOLÁS, G. etal. (Eds.). The biology of seeds: recent research advances. Cambridge: CAB International, 2003. p.259-70.

LABOURIAU, L.G. A germinação das sementes. Washington: OEA, 1983. 170p. (Série de Biologia. Monografia, 24).

LABOURIAU, L.G.; PACHECO, A. On the frequency of isothermal germination in seeds of Dolichos biflorus L.. Plant and Cell Physiology, v.19, n.3, p.507-12, 1978.

LARCHER, W. Ecofisiologia vegetal. São Carlos: Rima Artes e Textos, 2000.531p.

LORENZI, H.; MATOS, F.J.A. Plantas medicinais no Brasil: nativas e exóticas cultivadas. Nova Odessa: Instituto Plantarum, 2002. p.484.

MALUF, A.M.; PISCIOTTANO-EREIO, W.A. Secagem e armazenamento de sementes de Cambuci. Pesquisa Agropecuária Brasileira, v.40, n.7, p.707-14, 2005. MARCOS FILHO, J. Fisiologia de sementes cultivadas. Piracicaba: FEALQ, 2005. 495p.

MAYER, A.M.; POLJAKOFF-MAYBER, A. The germination of seeds. New York: Pergamon Press, 1982. 210p.

MELO, J.T.;RIBEIRO, J.F.; LIMA, V.L.G.F. Germinação de sementes de algumas espécies arbóreas nativas do cerrado. Revista Brasileira de Sementes, v.1, n.2, p.812, 1979.

POPINIGIS, F. Fisiologia das sementes. 2.ed. Brasília: S. n., 1985. 289p.

REDDY, K.N.; SINGH, M. Germination and emergence of hairy beggarticks (Bidens pilosa). Weed Science, v.40, n.2, p.195-9, 1992.

RODRIGUES, V.M. et al. Supercritical extraction of essential oil from aniseed (Pimpinella anisum L.) using 
$\mathrm{CO}_{2}$ : solubility, kinetics, and composition data. Journal of Agricultural and Food Chemistry, v.51, p.1518-23, 2003. STEFANELLO, R. et al. Influência da luz, temperatura e estresse hídrico na germinação e no vigor de sementes de anis. Revista Brasileira de Sementes, v.32, n.1, p.4550, 2006.

STORCK, L. et al. Experimentação vegetal. Santa Maria: Editora UFSM, 2000. 198p.

TESKE, M.; TRENTINI, A.M.M. Herbarium: compêndio de fitoterapia. Paraná: Herbarium Lab. Botânico, 1995. 317p. TORRES, S.B. Teste de envelhecimento acelerado em sementes de erva-doce. Revista Brasileira de Sementes, v.26 n.2, p.20-4, 2004.
UFSM. Armazenamento de sementes. Santa Maria: UFSM, 2004. Disponível em: <http://www.ufsm.br/ sementes/>. Acesso em: 7 ago. 2004.

VIEIRA, A.H. et al. Técnicas de produção de sementes florestais. Porto Velho: Embrapa, CT 205, 2001. p.1-4. VILLELA, F.A.; PERES, W.B. Coleta, beneficiamento e armazenamento. In: FERREIRA, A.G.; BORGHETTI, F.(Orgs.). Germinação: do básico ao aplicado. Porto Alegre:Artmed, 2004. p.265-81.

Von HERTWIG, I.F. Plantas aromáticas e medicinais: plantio, colheita, secagem, comercialização. São Paulo: Editora ĺcone, 1991.412p. 